This is a peer-reviewed, accepted author manuscript of the following chapter: Green, T., Su, X., \& Roy, S. (2021). Pulse electrodeposition of copper in the presence of a corrosion reaction. Journal of the Electrochemical Society, 168(6), [062515]. https://doi.org/10.1149/1945-7111/ac0a21

\title{
Pulse Electrodeposition of Copper in the Presence of a Corrosion Reaction
}

\author{
T.A. Green, X. Su and S. Roy \\ Department of Chemical and Process Engineering, University of Strathclyde, Glasgow, \\ Scotland G1 1XJ, United Kingdom.
}

\section{Corresponding author:}

Todd Green

Department of Chemical and Processing Engineering, University of Strathclyde, Glasgow,

G1 1XJ, United Kingdom

e-mail: todd.green@strath.ac.uk

\section{ORCID}

T.A. Green: https://orcid.org/0000-0002-3538-5217

S. Roy: https://orcid.org/0000-0002-3399-035X 


\begin{abstract}
This study has examined the pulse electrodeposition of copper from a deep eutectic solvent. Pulse plating parameters were selected using the methodologies originally developed for aqueous solutions, including constraints arising from double layer charging and mass transport effects. Although copper could be deposited under nearly all conditions, in many instances only partial plating was observed and current efficiencies were low. This effect was greatest at low duty cycles and/or when the off-time was long. This phenomenon was attributed to a corrosion (comproportionation) reaction occurring in the off-time. A simple model based on the corrosion reaction being under cathodic mass transport control was developed. While this could explain the main effects, it predicted a corrosion rate that was typically higher than observed. A variety of other models were then explored, the most plausible one indicating that the corrosion rate in the off-time is being controlled by a slow chemical dissolution step. This explained the main observations and predicts that, only for long pulse periods when steady-state conditions are approached, is the corrosion rate under cathodic mass transport control. Finally, it was found that benzotriazole could be employed to substantially reduce the corrosion rate and allow higher current efficiencies to be obtained.
\end{abstract}




\section{Introduction}

The deposition of thin films by pulse electrodeposition is a versatile surface finishing technique and has been widely used to deposit metals, alloys and semiconductors. By careful selection of pulse parameters it is possible to influence mass transport, kinetics and electrocrystallisation aspects of the deposition process and obtain deposits with compositions, morphologies and microstructures that are not attainable by conventional DC plating. Theoretical and experimental aspects of pulse electrodeposition have been reviewed into two monographs $\mathbf{1 , 2}$ and a number useful review articles ${ }^{3-5}$ have also been published. However, most studies of pulse electrodeposition have focused on the deposition of metals and binary alloys from aqueous solutions, and there have been relatively few studies from non-aqueous systems. In the former case, the most industrially important process is probably the pulse plating of copper, and this has been employed, for example, in the manufacture of PCBs, interconnects and in electroforming applications..$^{1-5}$

While the most important phenomena associated with pulse plating have been fully elucidated and a strong theoretical framework has been established, additional reactions and processes are still being identified. Traditionally in pulse plating the off-time is considered a relatively unimportant parameter, allowing, for example, relaxation of concentration gradients, desorption of additives, recrystallization and discharge of the double later capacitance, $\mathbf{1 , 2 , 4 , 5}$. However, more recent studies have shown that it is possible to have 'internal current' processes occurring in the off-time which can strongly influence the deposit properties. For example, in the pulse electrodeposition of binary alloys from aqueous solutions, displacement (corrosion) reactions have been observed in the off-time which can significantly alter the alloy composition $^{6-8}$. This has been observed in both aqueous ${ }^{6,7}$ and molten salt ${ }^{8}$ systems and appears 
a very general phenomenon. Corrosion processes during pulse plating which do not arise from displacement reactions have occasionally been suggested ${ }^{9}$, but their effects have not been investigated. Recently we observed corrosion arising from a comproportionation reaction during the pulse plating of copper from a non-aqueous system, and noted some initial characteristics in a preliminary publication. ${ }^{\mathbf{1 0}}$ The main purpose of this paper is to expand on those initial findings and develop a more comprehensive understanding of the corrosion process.

The electrodeposition of metals and alloys from deep eutectic solvents (DES) have also attracted recent interest. ${ }^{11,12}$ These materials have similar characteristics to conventional room temperature ionic liquids (RTILs) and allow the deposition of metals and alloys which are difficult to obtain from aqueous solutions. Compared to RTILs they possess some important advantages such as low cost, low volatility and toxicity, and good tolerance to water contamination. ${ }^{11,12}$ However, essentially all deposition studies from DES and RTIL systems have been performed under DC conditions and there have been relatively few investigations of pulse electrodeposition. ${ }^{13-15}$ The majority of these studies have focused on metals, but alloys have also been prepared and characterised. ${ }^{11}$

A limitation of many of these studies is that they employ relatively long pulses (typically seconds) which essentially correspond to steady-state conditions. ${ }^{11-15}$ At these timescales, many of the transient phenomena (e.g. double layer charging and non-steady state mass transport) associated with traditional pulse plating in the millisecond time domain are largely absent. $^{1-5}$ In addition, pulse parameters in these studies have mainly been selected on an empirical basis, and ignore constraints arising from double layer and mass transport effects. At the same time, DES systems ${ }^{\mathbf{1 1}, 12}$ have different characteristics to aqueous systems, especially 
in terms of mass transport, kinetics, conductivity and double layer structure and it is unlikely that pulse parameters developed for aqueous electrolytes are optimal for the latter. Therefore, a secondary aim is to use relatively short pulses and then apply the methodologies originally employed to calculate pulse parameters for aqueous systems to design suitable parameters for DES systems. 


\section{Experimental}

Electrochemical and Electrodeposition Measurements

The deep eutectic solvent ('ethaline') was prepared by mixing choline chloride (Sigma Aldrich, $>98 \%$ ) and ethylene glycol (Sigma Aldrich, purity $>98 \%$ ) in a 1:2 molar ratio, and then heating on a hotplate at $70^{\circ} \mathrm{C}$ until a transparent, homogenous melt was formed. The electrolyte was then prepared by dissolving hydrated cupric chloride salt $\left(\mathrm{CuCl}_{2} \cdot 2 \mathrm{H}_{2} \mathrm{O}\right.$, Merck, $\left.>99 \%\right)$ in the ethaline melt to prepare a $0.20 \mathrm{M}$ solution. In some experiments, benzotriazole (Sigma-Aldrich, $>99.9 \%$ ) was added to the electrolyte at a concentration of $5-10 \mathrm{mM}$ to act as a corrosion inhibitor. The water content of the DES was determined to be $<1 \mathrm{wt} \%$ by a Hybrid Karl Fischer titration.

All experiments were performed in a jacketed, one compartment glass cell, that was thermostated at $25^{\circ} \mathrm{C}$. The cell contained a copper rod counter electrode (Alfa, 99.999\%) and a silver wire (Aldrich, 99,9\%) quasi-reference electrode. The Ag wire was mounted in a fritted glass tube containing pure ethaline and isolated from the main solution by a porous glass frit. For the electrodeposition studies, the working electrode was a low-alloy steel disk (area $=1.2$ $\mathrm{cm}^{2}$ ) that was mounted in a PEEK substrate holder (Origalys). Steady-state voltammetry was performed at a conventional a Pt disk electrode $\left(\right.$ area $\left.=0.031 \mathrm{~cm}^{2}\right)$ mounted in PTFE. Before each experiment, the electrodes were polished with 2400 and 4000 grade $\mathrm{SiC}$ paper, rinsed with water and dried with $\mathrm{N}_{2}$. Both the steel and Pt electrodes could be rotated using a combined EDI101 electrode rotator and CTV101 controller (Radiometer Analytical).

Polarisation and electrodeposition experiments were performed using a potentiostat (PGSTAT30, Metrohm Autolab) in a conventional three-electrode set-up. For the pulse 
electrodeposition experiments, the potentiostat was operated in galvanostatic mode, with the rectangular pulse waveforms being defined in the Nova 2.0 software. During the experiments, the WE-RE potential and the cell current were measured every $250 \mu$ s. A combined potentiostat and impedance analyser (Palmsens 4) was also employed to measure the double layer capacitance, $C_{\mathrm{dl}}$, of the electrode and the uncompensated resistance, $R_{\mathrm{u}}$. Impedance spectra were obtained in the range $2.5 \mathrm{~Hz}$ to $10 \mathrm{kHz}$ with a $10 \mathrm{mV}$ amplitude and then fitted with an equivalent circuit consisting of a CPE and a parallel and series resistance. A value of $C_{\mathrm{dl}}=15$ $\mu \mathrm{F} \mathrm{cm}$-2 was obtained in a solution of $0.2 \mathrm{M} \mathrm{CuCl}_{2}$ in ethaline at a potential of $-0.60 \mathrm{~V}$, while $C_{\mathrm{dl}}=18 \mu \mathrm{F} \mathrm{cm}^{-2}$ was measured in pure ethaline. These values are in good agreement with recent differential capacitance measurements of carbon, Pt and Au electrodes in ethaline. ${ }^{\mathbf{1 6}}$

The current efficiency, $\varepsilon$, for each experiment was determined gravimetrically, and the deposit morphology was examined using optical microscopy. Additionally, one sample $\left(\mathrm{t}_{\mathrm{on}}=10 \mathrm{~ms}, \theta\right.$ $=0.67)$ was cross-sectioned to examine its thickness distribution. Prior to sectioning, this was plated to a nominal $\mathrm{Cu}$ thickness of $10 \mu \mathrm{m}$ and then over-plated with $20 \mu \mathrm{m}$ of Ni to aid edge retention. Deposit thickness was measured using a Brunel SP400 metallurgical microscope at a magnification of $\times 500$. Images of the deposit cross-sections were performed using a Hitachi S-3800 SEM at a magnification of $\times 1000$.

\section{Selection of Pulse Parameters for Electrodeposition}

Pulse parameters were selected using the methodologies described previously., ${ }^{2,17}$ After choosing pulse on times, $t_{\mathrm{on}}$, and appropriate duty cycles, $\theta$, steady-state and transient mass transport constraints were then imposed. These were based on the known DC limiting current density, $i_{\mathrm{LIM}}=6.2 \mathrm{~mA} \mathrm{~cm}^{-2}$ at $\omega=700 \mathrm{rpm}$, measured in steady-state polarisation experiments, 
and the pulse limiting current, $i_{\mathrm{pLIM}}$, calculated using the equations proposed by Roy and Landolt. ${ }^{18,19}$ These effectively set the value of the peak current, $i_{\mathrm{p}}$, in the experiments. These two constraints can be conveniently represented by the dimensionless numbers: $\mathrm{N}_{\mathrm{m}}=\theta i_{\mathrm{p}} / i_{\mathrm{LIM}}$ and $\mathrm{N}_{\mathrm{p}}=i_{\mathrm{p}} / i_{\mathrm{pLIM}}$. Previous studies ${ }^{\mathbf{1 8 , 2 0}}$ of copper deposition from aqueous solutions have shown that that compact, granular deposits and high current efficiencies can only be obtained for the condition of $\mathrm{N}_{\mathrm{m}}<1$ and $\mathrm{N}_{\mathrm{p}}<1$. It was therefore decided to set $\mathrm{N}_{\mathrm{p}}=0.80$ as this ensures that the mass transport limitations for pulse conditions are constant for all experiments. This constraint resulted in $\mathrm{N}_{\mathrm{m}}$ values of between 0.47 and 0.79 . Note that on theoretical grounds it is not possible to simultaneously assign both $\mathrm{N}_{\mathrm{m}}$ and $\mathrm{N}_{\mathrm{p}}$ to constant values.

The final pulse parameters chosen in the experiments are summarised in Table I. Essentially four pulse on-times were chosen ( $t_{\text {on }}=10,50,100$ and $\left.200 \mathrm{~ms}\right)$ and four duty cycles $(\theta=0.20$, $0.30,0.50$ and 0.67$)$ resulting in a matrix of 16 experiments. The duration of each experiment was chosen to correspond to a deposition charge of $14 \mathrm{C} \mathrm{cm}^{-2}$. This corresponds to a nominal copper deposit thickness of $5 \mu \mathrm{m}$, if the current efficiency were equal to unity.

An additional constraint on the selection of pulse parameters is the time required to charge and discharge the double layer capacitance, $C_{\mathrm{dl} .}{ }^{\mathbf{1}, \mathbf{2}}$ On practical grounds, the charging time, $t_{\mathrm{c}}$, must be shorter than the pulse on-time, $t_{\mathrm{on}}$, otherwise the faradaic current is distorted. For similar reasons, the discharge time, $t_{\mathrm{d}}$, must be shorter than the pulse off-time, $t_{\mathrm{off}}$. These two parameters were calculated using a Matlab routine that implemented the original model developed by Ibl and Puippe. ${ }^{17,21}$ This approach requires knowledge of the kinetic parameters (transfer coefficient, $\alpha$, and exchange current density, $i_{0}$ ) for the deposition reaction and the double layer capacitance. In the present case, the double layer charging is controlled by the kinetically slow second step: $\mathrm{CuCl}_{2}^{-}+\mathrm{e}-\rightarrow \mathrm{Cu}+2 \mathrm{Cl}^{-}$. In a previous study ${ }^{22}$ values of $\alpha_{\mathrm{c}}=$ 
0.42 and $i_{0}=5.7 \mathrm{~mA} \mathrm{~cm}^{-2}$ were determined for this for this reaction. Using these values and a measured double layer capacitance of $C_{\mathrm{dl}}=15 \mu \mathrm{F} \mathrm{cm}$, the charge and discharge times were estimated. These calculations indicated that $t_{\mathrm{c}}$ and $t_{\mathrm{d}}$ are typically in the range $0.22-0.34 \mathrm{~ms}$ (Table I) which is much lower than the shortest on and off times $(10 \mathrm{~ms})$. This indicates that double layer charging effects are not significant under the present pulse conditions. 


\section{Results and Discussion}

Comparison of DES and Aqueous Systems for Pulse Plating

Firstly, it is instructive to compare the pulse conditions accessible for the DES system with an equivalent aqueous (acid copper) system ${ }^{\mathbf{1 8 , 2 0}}$ under identical hydrodynamic conditions $(\omega=$ $700 \mathrm{rpm}$ ). For these illustrative calculations (Table II) we have assumed $t_{\mathrm{on}}=50 \mathrm{~ms}$ and $\theta=$ 0.50. The data in Table II clearly shows some of the limitations of the DES system for pulse electrodeposition. Both $i_{\text {LIM }}$ and $i_{\text {pLIM }}$ are much lower, mainly reflecting the low diffusion coefficient of the copper species in ethaline, and this restricts the maximum plating rate to around $6 \%$ of the aqueous system. The thickness uniformity, quantified by the Wagner (Wa) number ${ }^{\mathbf{1}, \mathbf{2}}$, is also much lower in the DES even though plating is performed at a much lower peak current density. This mainly reflects the relatively low conductivity of the DES electrolyte. The charge and discharge time are, however, comparable to the acid copper systems as the lower $i_{\mathrm{p}}$ for ethaline is compensated by a lower value of $C_{\mathrm{dl}}$.

\section{Initial Polarisation Experiments}

To assist in the selection of pulse parameters and to understand the important electrochemical characteristics of the $\mathrm{CuCl}_{2}$-ethaline system, some initial voltammetric measurements were performed. Figure 1, for example, shows the steady-state voltammogram for $0.20 \mathrm{M} \mathrm{CuCl}_{2}$ in ethaline at a platinum $\operatorname{RDE}(\omega=700 \mathrm{rpm})$. The cathodic scan shows two limiting current plateaux that correspond to the step-wise reduction of $\mathrm{Cu}(\mathrm{II})$ and $\mathrm{Cu}(\mathrm{I})$ chloro-complexes. For the anodic scan, a copper stripping peak is observed forming the $\mathrm{Cu}(\mathrm{I})$ complex which is subsequently oxidised back to the $\mathrm{Cu}$ (II) complex. There is a general consensus ${ }^{23-26}$ that the overall electrochemical reactions corresponding to these steps are: 
Additional studies (not shown) indicated that each current plateau increased linearly with $\omega^{1 / 2}$ indicating that both reductions occur under mass transport control ${ }^{22}$. Interestingly, the data also indicate that, under open circuit conditions, the first cathodic step could couple with the dissolution step to form a 'mixed' couple. This suggests the possibility of a corrosion reaction in the $\mathrm{CuCl}_{2}$-ethaline system.

\section{Pulse Electrodeposition Experiments}

After the voltammetric study, pulse electrodeposition experiments were performed under conditions corresponding to the matrix defined in Table I. The results of this study are summarised in Figure 2 which shows the deposit characteristics and Figure 3 which indicates the measured current efficiency. Figure 2 indicates that, under some pulse conditions, only partial plating is observed. Typically, a copper annulus was observed at the edges of the disc with the steel substrate exposed at the centre. This effect became more pronounced for short duty cycles and for long off-times. In fact, for duty cycles of $\theta=0.10$ (data not shown) it was impossible to deposit copper under any conditions, and only a relatively long duty cycles $(\theta>$ 0.50) was it possible to observe a continuous copper film over the entire substrate. The measured current efficiency data also reflect a similar trend. In the case of short duty cycles $(\theta$ $<0.30$ ) low or even 'negative' current efficiencies were observed. This is in contrast to 
electrodeposition experiments performed at high duty cycles and short off-times which showed current efficiencies approaching those seen under DC conditions (i.e. $\varepsilon=0.78$ ).

A likely explanation for these results is that a corrosion reaction is occurring in the off-time, and the voltammetric data in Figure 1 already suggests that this is a possibility. There is clearly a balance between deposition in the on-time and dissolution in the off-time and this qualitatively explains the partial plating and low $\varepsilon$ values when $\theta$ is low and/or the off-time is long. The 'annulus' effect arises primarily because the material distribution at a RDE is generally not uniform ${ }^{27}$, and this effect is known to be more pronounced for pulse versus DC plating. ${ }^{1-3}$ Even if the corrosion of copper in the off-time is more or less uniform across the substrate, it is likely that the thinner deposit at the centre will be removed earlier. Similarly, the apparent negative current efficiencies are likely to arise from corrosion of the underlying steel substrate. Note that the low current efficiencies observed cannot be attributed to steadystate or transient mass transport limitations being exceeded as in all cases $\mathrm{N}_{\mathrm{m}}<1$ and $\mathrm{N}_{\mathrm{p}}<1$.

To assess the effect of the non-uniform current distribution at the RDE, the thickness distribution as a function of the radial position for a DC and pulse plated sample $\left(t_{\mathrm{on}}=10 \mathrm{~ms}\right.$, $\theta=0.67)$ was measured. This is shown in Figure 4 along with the theoretical primary current distribution for a recessed RDE. ${ }^{28}$ It can be seen that the DC plated sample has a current distribution that closely matches the primary one, even though the calculated Wagner number $\left(\mathrm{W}_{\mathrm{a}} \approx 0.17\right)$ indicates some secondary character. This indicates the centre is expected to have $50 \%$ of the thickness at the edge, which is a plausible explanation for the annulus effect. The pulse plated sample (for which $\mathrm{W}_{\mathrm{a}} \approx 0.10$ ) shows a large centre to edge thickness variation but in this case it reflects the combined effects of deposition and dissolution. Interestingly, the edge to centre thickness variation appears even greater than for a primary current distribution. This 
suggests that the corrosion reaction is not occurring uniformly and proceeds faster at the centre than at the edge. Figure 5 shows the SEM cross-section for the same pulse plated sample at the edge and centre and again illustrates these large thickness variations.

As noted in our previous publications ${ }^{10,29}$, the most likely candidate for the corrosion process is the comproportionation reaction involving $\mathrm{Cu}$ and the $\mathrm{Cu}(\mathrm{II})$ chloro-complex:

$\mathrm{Cu}+\mathrm{CuCl}_{4}^{2-} \rightarrow 2 \mathrm{CuCl}_{2}^{-}$

This arises from the following coupled cathodic and anodic reactions:

$\mathrm{CuCl}_{4}^{2-}+\mathrm{e}-\rightarrow \mathrm{CuCl}_{2}^{-}+2 \mathrm{Cl}^{-}$

$\mathrm{Cu}+2 \mathrm{Cl}^{-} \rightarrow \mathrm{CuCl}_{2}^{-}+\mathrm{e}-$

This is consistent with the voltammetric data in Figure 1. We have previously shown that this reaction occurs at copper anodes in the $\mathrm{CuCl}_{2}$-ethaline system, and that copper corrosion by $\mathrm{O}_{2}$ is negligible under such conditions. ${ }^{29}$ Corrosion by comproportionation processes have also been seen in aqueous systems, and the etching of copper by $\mathrm{CuCl}_{2}$ solutions routinely used to manufacture PCBs is a notable example. ${ }^{30}$ Similarly, during the pulse plating of copper from concentrated $\mathrm{HCl}$ solutions, corrosion due to comproportionation was observed. ${ }^{31}$ This initially led to the formation of an insoluble $\mathrm{CuCl}$ salt film, but at long off-times it dissolved to form soluble chloro-complexes. 
Some additional evidence for the corrosion reaction can be seen in the time dependence of the electrode potential, $E$, during the pulse cycle. For example, Figure 6 shows this for a fixed ontime $\left(t_{o n}=200 \mathrm{~ms}\right)$ and at various duty cycles. In the off-time, the electrode potential initially drops to a value of $E \approx-0.20 \mathrm{~V}$. Based on the voltammetric data (Figure 1) it might be expected that the potential assumes a value of $E \approx+0.60 \mathrm{~V}$ corresponding to the zero current position. Instead it attains a potential which corresponds to the mixed (corrosion) potential value of half reactions [4] and [5]. However, at longer off-times the potential gradually transitions to a value of $E=-0.10 \mathrm{~V}$ which corresponds to the measured corrosion potential, $E_{\text {corr, }}$ of steel. The effect is particularly noticeable for the two experiments performed at $\theta=0.20$ and $\theta=0.30$. This indicates that at sufficiently long times the copper can be completely removed from the steel substrate.

\section{Metal Dissolution Experiments}

Once the corrosion reaction had been identified, the next step was to determine its rate under steady-state conditions. To estimate this, a copper $\mathrm{RDE}$ was immersed in the $\mathrm{CuCl}_{2}$-ethaline electrolyte and the weight loss was monitored over a periods of $10-20 \mathrm{~min}$. These studies showed that the corrosion rate increased linearly with the square root of the rotation rate indicating the process was under mass transport control. The value of $E_{\text {corr }}$ also became more positive with increasing rotation suggesting that the cathodic reaction is under mass transport control.

This is consistent with our proposed corrosion process with cathodic half-reaction [4] controlling the overall rate (i.e. $i_{\text {corr }}=i_{\text {LIM }}$ ). At a rotation rate of $\omega=700 \mathrm{rpm}$ the measured

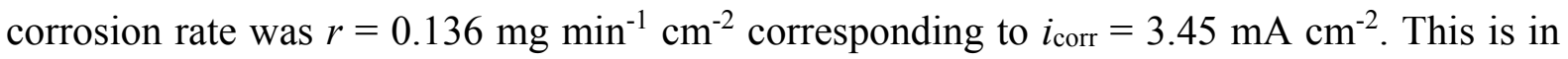


good agreement with the limiting current density of $i_{\text {lim }}=3.65 \mathrm{~mA} \mathrm{~cm}^{-2}$ measured at $\omega=700$ rpm for reaction [4] (Figure 1). It was also found that the steel substrate could corrode in the electrolyte, but the rate was $70 \%$ lower than that for copper. Assuming that these values reflect the corrosion rate during the actual off-time, it should be possible to quantify the corrosion effects and changes in current efficiency observed in the pulse plating experiments.

\section{Corrosion Models}

The simplest model that can be conceived is one where corrosion occurs at a constant rate $\left(i_{\text {corr }}\right)$ in the off-time. Under these conditions the current efficiency, $\varepsilon$, can be related to the pulse parameters as follows:

$$
\varepsilon=\varepsilon^{\prime}-2 i_{\text {corr }} t_{\mathrm{off}} / i_{\mathrm{p}} t_{\mathrm{on}}
$$

where $\varepsilon^{\prime}$ is the current efficiency during the on-time. Noting that $\theta=t_{\text {on }} /\left(t_{\text {on }}+t_{\text {off }}\right)$ this expression can be rewritten purely in terms of the duty cycle:

$$
\varepsilon=\varepsilon^{\prime}-2 i_{\text {corr }}(1-\theta) / i_{\mathrm{p}} \theta
$$

Therefore, a plot of $\varepsilon$ versus $2(1-\theta) / i_{\mathrm{p}} \theta$ should result in a straight line with an intercept of $\varepsilon$ ' and slope of $i_{\text {corr. }}$ The results of such calculations are shown in Figure 7 and Table III. While the results qualitatively support the proposed model, they indicate that $i_{\text {corr }}$ show a dependence on the pulse conditions. Moreover, the value of $i_{\text {corr }}$ seems to increase as the overall pulse duration increases. Also shown is the behaviour expected if $i_{\text {corr }}=3.45 \mathrm{~mA} \mathrm{~cm}^{-2}-$ the value determined in the steady-state dissolution experiments. It is clear that the corrosion rate extracted from the current efficiency data is significantly lower than this. This indicates that 
the corrosion process is more complex and that the condition of a constant dissolution rate in the off-time is not valid.

While it would be difficult to directly measure the time dependence of the corrosion rate during the off-time, it can be inferred from the measured value of $E$. Once the double layer capacitance has discharged $(<0.5 \mathrm{~ms})$ it is a reasonable assumption that $E \approx E_{\text {corr, }}$ provided that only copper is exposed to the electrolyte. Figure 8 shows some typical potential transients in the off-time corresponding to duty cycles of $\theta=0.50$. It is clear that the potential is not constant in the offtime and there is a general trend for it to become more positive. This suggests that the corrosion in the off-time starts at a low (or zero) value and increases through the off-time. The same trend is also visible in Figure 6. This is in contrast to the pulse plating of binary alloys where the corrosion rate by displacement reaction tends to slow over the off-time due to surface enrichment with the noble component. ${ }^{6,7}$

It is also possible that some of these effects could relate to the non-steady diffusion that prevails during pulse plating. ${ }^{\mathbf{1 , 2 , 3 , 5}}$ It is expected that, during the on-time, that $\mathrm{CuCl}_{4}{ }^{2-}$ complex is always being reduced under limiting current conditions. Normally the concentration gradient would relax in the off-time resulting in a reduced flux of the $\mathrm{CuCl}_{4}{ }^{2-}$ species to surface, and this would tend to decrease the corrosion rate. In the presence of a corrosion reaction, $\mathrm{CuCl}_{4}^{2-}$ would continue to be consumed at the electrode and its surface concentration would likely be pinned to a value near zero. Whatever the exact circumstances it seems likely that, if the reduction of $\mathrm{CuCl}_{4}{ }^{2-}$ is controlling the corrosion rate, it would either be relatively constant or declining in the off-time. This is not in agreement with the finding that the corrosion rate appears to be increasing through the off-time. 
Another possible explanation for the results shown in Figure 7 is that, for some fraction of the off-time, corrosion does not occur due to some inhibiting (e.g. film formation) process. It is therefore instructive to calculate the 'dead' time which would result in a behaviour consist with $i_{\text {corr }}=3.45 \mathrm{~mA} \mathrm{~cm}^{-2}$. Such calculations indicate for the required dead time would typically be $30-60 \%$ of $t_{\text {off }}$ with no obvious trend with pulse conditions. Moreover such a model would require the $E$ measured in the off time to transition from 'no corrosion' to corrosion in a stepwise manner, whereas the data show a continuous change in $E$ in the off-time. Figure 9 shows schematically the expected potential variations for the 'no corrosion', constant corrosion and dead-time models and clearly none are consistent with the observed behaviour of the potential in the off-time.

From this analysis, it appears that the observed results cannot be fully quantified and some additional complexities must be present. One possibility is that, under transient conditions, there are kinetic limitations associated with the anodic or cathodic processes which essentially disappear under steady-state conditions. This could explain the general trend that for long pulse periods the corrosion rate approaches the value measured in steady-state dissolution experiment. To explore this further, it is necessary to examine in more detail the electrochemical and chemical processes occurring during the on and off time.

It is generally assumed ${ }^{22-26}$ that the reactions in DES are similar to those in high-chloride aqueous systems, and this is the approach taken here. According to $\mathrm{RaO}^{\mathbf{3 2}}$, the steps leading to the deposition of $\mathrm{Cu}$ (equation [2]) from $\mathrm{Cu}(\mathrm{I})$ chloro-complexes in aqueous systems (acidic and high chloride) can be represented by the overall mechanism:

$\mathrm{CuCl}_{2}^{-} \rightarrow \mathrm{CuCl}_{\text {ads }}+\mathrm{Cl}-$ 
$\mathrm{CuCl}_{\text {ads }}+\mathrm{e}-\rightarrow \mathrm{Cu}+\mathrm{Cl}^{-}$

$\mathrm{CuCl}_{\text {ads }}+\mathrm{Cl}^{-} \rightarrow \mathrm{CuCl}_{2}^{-}$

During the on-time the $\mathrm{CuCl}_{\text {ads }}$ species formed on the surface can be directly reduced to $\mathrm{Cu}$ or be dissolved by $\mathrm{Cl}^{-}$to form $\mathrm{CuCl}_{2}^{-}$, and the current efficiency in the on-time will therefore depend on the relative rates of these processes. The data in Table III indicate $\varepsilon^{\prime}=0.70-0.75$ suggesting a significant loss in current efficiency from dissolution. The surface coverage, $\theta$, of the $\mathrm{CuCl}_{\text {ads }}$ intermediate will also depend on the relative rates of the three processes. Note that the potentials in the on-time (Figure 6) generally does not reach a steady-state value even for very long on-times $(>0.2 \mathrm{~s})$. This is indicative of the presence of an adsorbed intermediate species (e.g. $\mathrm{CuCl}_{\text {ads }}$ ) whose coverage varies with time. ${ }^{2}$

In the presence of a corrosion reaction, there will be coupled anodic and cathodic half reactions occurring in the off-time. The mechanism of the anodic dissolution step is well established from aqueous studies ${ }^{33-35}$ and can be represented as:

$\mathrm{Cu}+\mathrm{Cl}^{-} \rightarrow \mathrm{CuCl}_{\mathrm{ads}}+\mathrm{e}-$

$\mathrm{CuCl}_{\mathrm{ads}}+\mathrm{Cl}^{-} \rightarrow \mathrm{CuCl}_{2}^{-}$

Some aqueous models ${ }^{31,33-35}$ also assume the formation of a $\mathrm{CuCl}$ salt film, but previous studies $^{29,36}$ of copper in ethaline indicate that this would typically require an anodic current density in excess of $40 \mathrm{~mA} \mathrm{~cm}{ }^{-2}$, far greater than that encountered in the present experiments. Therefore, in the DES system a corrosion process mediated by the formation and dissolution of a salt film can be discounted. Figure 10 summarises the main electrochemical and chemical processes that are believed to be occurring in the on and off-times. 
In order to explain the observed results in Figure 7, it is useful to consider some limiting cases of the corrosion mechanism in the off-time (Figure 10). Firstly, it is assumed that there is some initial coverage, $\theta$, of $\mathrm{CuCl}_{\text {ads }}$ intermediate at the end of the on time, which is governed but the kinetics of reactions [8], [9] and [10]. In the off-time, corrosion can occur and the rate of the anodic process, $v_{\mathrm{a}}$, is equal to the rate of the cathodic process, $v_{\mathrm{c}}$, and these will establish the time-dependent value of the coverage, $\theta$. Note also that $v_{\mathrm{a}}$ and $v_{\mathrm{c}}$ will generally depend on (1 - $\theta)$ the free surface sites available. ${ }^{34,35}$

If it is assumed that the rate of chemical dissolution (reaction [12]) is fast, so that that reaction [11] leading to the formation of $\mathrm{CuCl}_{\mathrm{ads}}$ is rate determining, then it is expected that the surface coverage of the intermediate would be low $(\theta \rightarrow 0)$ and relatively constant in the off-time. The dissolution rate $v=k \theta\left[\mathrm{Cl}^{-}\right]$would also be relatively constant in the off-time. If, however, reaction [11] was fast so that [12] was rate limiting, it would be anticipated that the surface coverage, $\theta$, would increase during the off-time until the rates of [11] and [12] are equal, and the dissolution rate $v=k \theta\left[\mathrm{Cl}^{-}\right]$would also increase. This second mechanism is more consistent with the experimental observations. Note that the requirements for a low or zero corrosion rate at the start of the off-time suggests that the surface coverage, $\theta$, at the end of the on-time must necessarily be low $(\theta \rightarrow 0)$.

While this model is speculative and would need further confirmation, it does qualitatively explain the main effects observed in the pulse plating trials. It suggests that under transient conditions, the rate of dissolution is under kinetic control, and the rate limiting step is the dissolution of the $\mathrm{CuCl}_{\text {ads. }}$. However, at longer times when steady-state conditions prevail it transitions to being under mass transport control by via the $\mathrm{CuCl}_{4}{ }^{2-}$ species. This is consistent 
with the data in Figure 7 which show that the corrosion rate is increasing with pulse period and approaching the mass transport limit.

\section{Effect of BTA Additive}

In order to minimise corrosion during pulse electrodeposition, the possibility of using a corrosion inhibitor was also explored. In the pulse plating of $\mathrm{Cu}-\mathrm{Co}$ alloys, for example, it has been shown ${ }^{37}$ that additives such as saccharin can be used to inhibit the corrosion rate caused by displacement in the off-time. In aqueous systems, a common inhibitor for copper is benzotriazole (BTA) and the mechanism of inhibition is generally thought to be due to the formation of a surface complex with copper. ${ }^{38}$ BTA has also been used ${ }^{39}$ as an additive for DC and pulse plating of copper from aqueous systems and it seemed a plausible candidate as an additive in the $\mathrm{CuCl}_{2}$-ethaline system. Laboratory trials also indicated that benzotriazole has a reasonable solubility $(\sim 20 \mathrm{mM})$ in the DES electrolyte.

Initial dissolution trials at a copper $\operatorname{RDE}(\omega=700 \mathrm{rpm})$ indicated a corrosion rate of $i_{\text {corr }}=1.12$ $\mathrm{mA} \mathrm{cm}{ }^{-2}$ in $0.20 \mathrm{M} \mathrm{CuCl}_{2}$ in ethaline containing $10 \mathrm{mM}$ BTA. This is approximately $30 \%$ of the rate in the absence of BTA $\left(i_{\text {corr }}=3.45 \mathrm{~mA} \mathrm{~cm}^{-2}\right)$ indicating that BTA is acting as an effective inhibitor under steady-state conditions. To verify this further, some additional pulse plating experiments were performed at on-times of $10 \mathrm{~ms}$ and $100 \mathrm{~ms}$ and with varying duty cycles. These experiments used pulse parameters identical to those used in the original trials. These experiments showed significant improvements in the current efficiency (Figure 11) under all pulse conditions, indicating that BTA can substantially mitigate the effects of corrosion in the off-time. 
The only issue noted was that the roughness of the deposits was significantly higher in the presence of BTA (Figure 12). A subsequent voltammetric study investigation revealed the likely cause. In the presence of BTA the limiting current for both the reduction of both the $\mathrm{Cu}(\mathrm{II})$ and $\mathrm{Cu}(\mathrm{I})$ complexes is reduced, resulting in a value of $i_{\text {lim }}$ that are significantly $(40 \%)$ lower than that originally used to define the pulse parameters. This effect has also been noted for copper deposition in aqueous systems. ${ }^{40}$ Using this revised value, $\mathrm{N}_{\mathrm{m}}$ and $\mathrm{N}_{\mathrm{p}}$ values could be recalculated for each pulse conditions used in the BTA trials. In most instances $\mathrm{N}_{\mathrm{m}} \approx 0.9-$ 1.1 , and $\mathrm{N}_{\mathrm{p}}=1.1$ under all conditions. So the observed surface roughness primarily arises because DC or pulse mass transport limits were approached or exceeded. However, even under these conditions it was still possible to attain relatively high current efficiencies.

\section{Conclusions}

This study has involved an examination of the pulse electrodeposition of copper from a chloride-containing deep eutectic solvent. Pulse plating parameters were selected using existing methodologies developed for aqueous solutions, and included constraints arising from steady-state and non steady-state mass transport, and also double layer charging and discharging effects. Unlike most other previous pulse plating studies performed in deep eutectic solvents (DES) and room temperature ionic liquids (RTIL) systems, this study employed relative short pulses where such transient effects are likely to be important. Our analysis reveals some limitations in applying pulse plating to DES systems, and notably the deposition rate will be typically much lower and thickness uniformity inferior compared to aqueous electrolytes under comparable conditions. However, relatively short pulses $(<10 \mathrm{~ms})$ are feasible in the DES system as double layer charge/discharge times are similar to aqueous systems. 
Initial pulse plating experiments showed that, although copper could be deposited under most conditions, in many instances only partial plating was observed and current efficiencies were low compared to those obtained under DC conditions. This effect was greatest at low duty cycles and/or when the off-time was relatively long, and as a result these pulse plating conditions are largely inaccessible. This phenomenon was attributed to a corrosion reaction occurring in the off-time, namely the comproportionation reaction: $\mathrm{Cu}+\mathrm{CuCl}_{4}{ }^{2-} \rightarrow 2 \mathrm{CuCl}_{2}^{-}$. Voltammetric studies, potential measurements in the off-time and the copper dissolution trials were also consistent with this hypothesis.

A model was developed to elucidate the observed dependence of the current efficiency on pulse parameters. This was based on the assumption that corrosion occurred continuously in the offtime and the rate was controlled by the mass transport of the $\mathrm{CuCl}_{4}{ }^{2-}$ species to the surface. While this could explain some of the main effects, it predicted a corrosion rate that was higher than observed. A variety of other models were then explored, but it was demonstrated that neither steady-state or transient mass transport effects, nor a 'dead-time' model could fully explain the experimental results. An alternative model involving a rate limiting chemical dissolution step was then proposed. This predicted an initially slow corrosion rate which then accelerates during the off-time as the surface coverage of the intermediate increases, and was consistent with experimental observations. Only for long pulse periods where steady-state conditions are approached is the rate controlled by mass transport of $\mathrm{CuCl}_{4}{ }^{2-}$.

It should be noted that the corrosion effects seen in this pulse plating study are quite general and are possible in any system where there is a stable, intermediate valency species. This would be possible, for example, in aqueous-based, RTIL or molten salt systems. Importantly, it is not 
restricted to comproportionation reactions, and a very early study ${ }^{9}$ of gold pulse plating from a cyanide electrolyte exhibited anomalous behaviour at short duty cycles consistent with $\mathrm{O}_{2}$ induced corrosion during the off-time. Other cyanide-based aqueous electrolytes (e.g. Ag and $\mathrm{Cu})$ are also likely to be prone to corrosion in the off-time in the presence of oxygen. These effects will be largest when the corroding species has a high concentration and the overall plating rate relatively low.

Finally, in terms of minimising corrosion effects in pulse plating, a number of options are available. Firstly, it could be reduced by operating at fairly long duty cycles (i.e. $\theta>0.50$ ) and short on-times. However, this limits the parameter space where the process can be optimised and, in effect, DC conditions are being approached. It may also be possible to maintain the current or potential in the off-time to a value that prevents dissolution, but allows for minimal deposition. Finally, the use of corrosion inhibitors such as benzotriazole can be implemented. These would be particularly attractive if they could function both as an inhibitor and as an additive (levelling or brightening agent). 


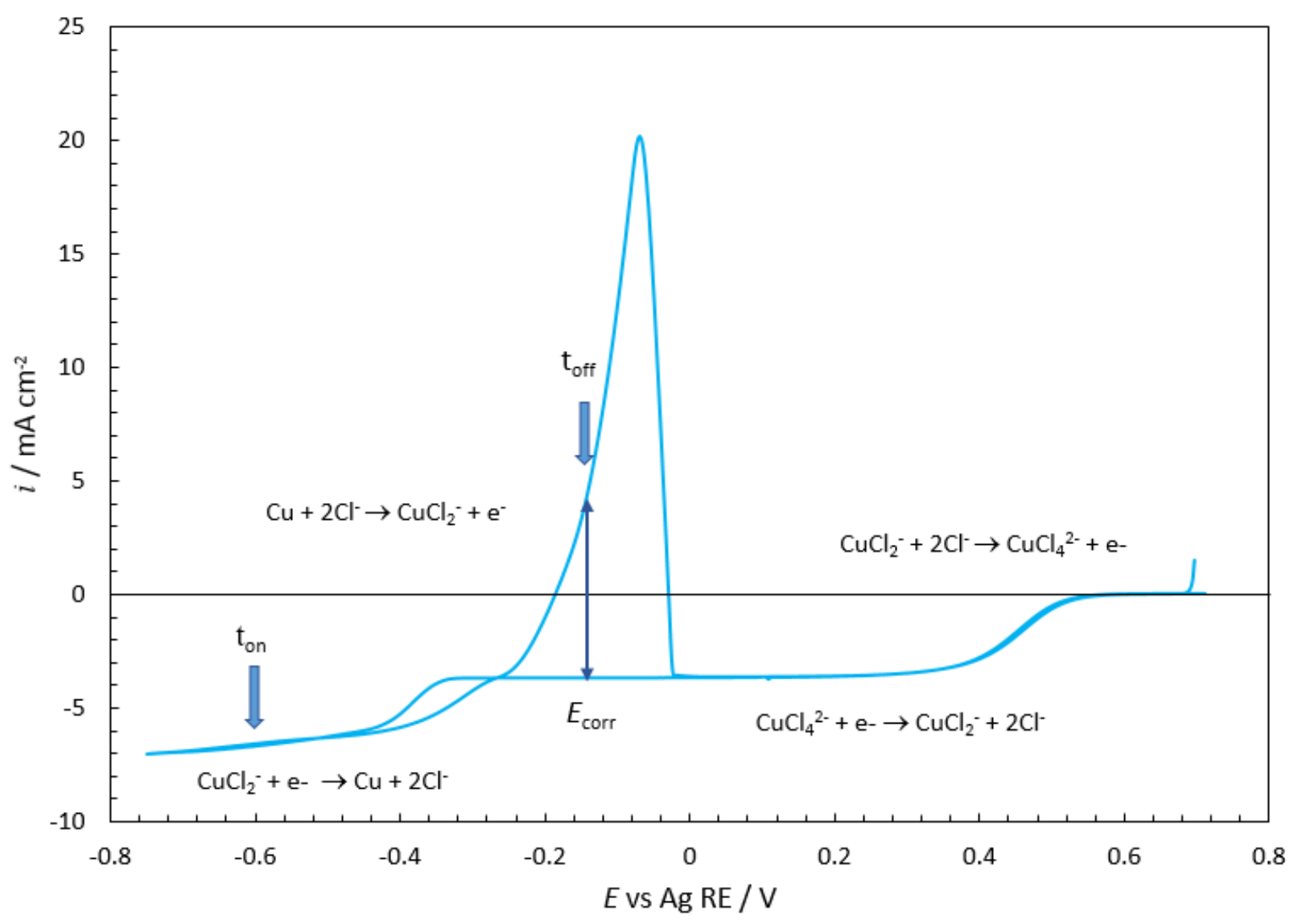

Figure 1: Steady state voltammogram of $0.20 \mathrm{M} \mathrm{CuCl}_{2}$ in ethaline at $25{ }^{\circ} \mathrm{C}$. The scan rate was $5 \mathrm{mV} \mathrm{s}^{-1}$ and $\omega=700 \mathrm{rpm}$. This data has been $I R$ corrected by positive feedback $(90 \%$ compensation). The approximate positions of the on and off-times for the pulse plating experiments and the corrosion potential are also shown. 


\begin{tabular}{|l|l|l|l|l|}
\hline & $\mathrm{t}_{\text {on }}=10 \mathrm{~ms}$ & $\mathrm{t}_{\text {on }}=50 \mathrm{~ms}$ & $\mathrm{t}_{\text {on }}=100 \mathrm{~ms}$ & $\mathrm{t}_{\text {on }}=200 \mathrm{~ms}$ \\
\hline$\theta=0.2$ & & & & \\
\hline$\theta=0.3$ & & & & \\
\hline$\theta=0.5$ & & & & \\
\hline
\end{tabular}

Figure 2: Images of electrodeposited copper from $0.2 \mathrm{M} \mathrm{CuCl}_{2}$ in ethaline as a function of pulse parameters. 


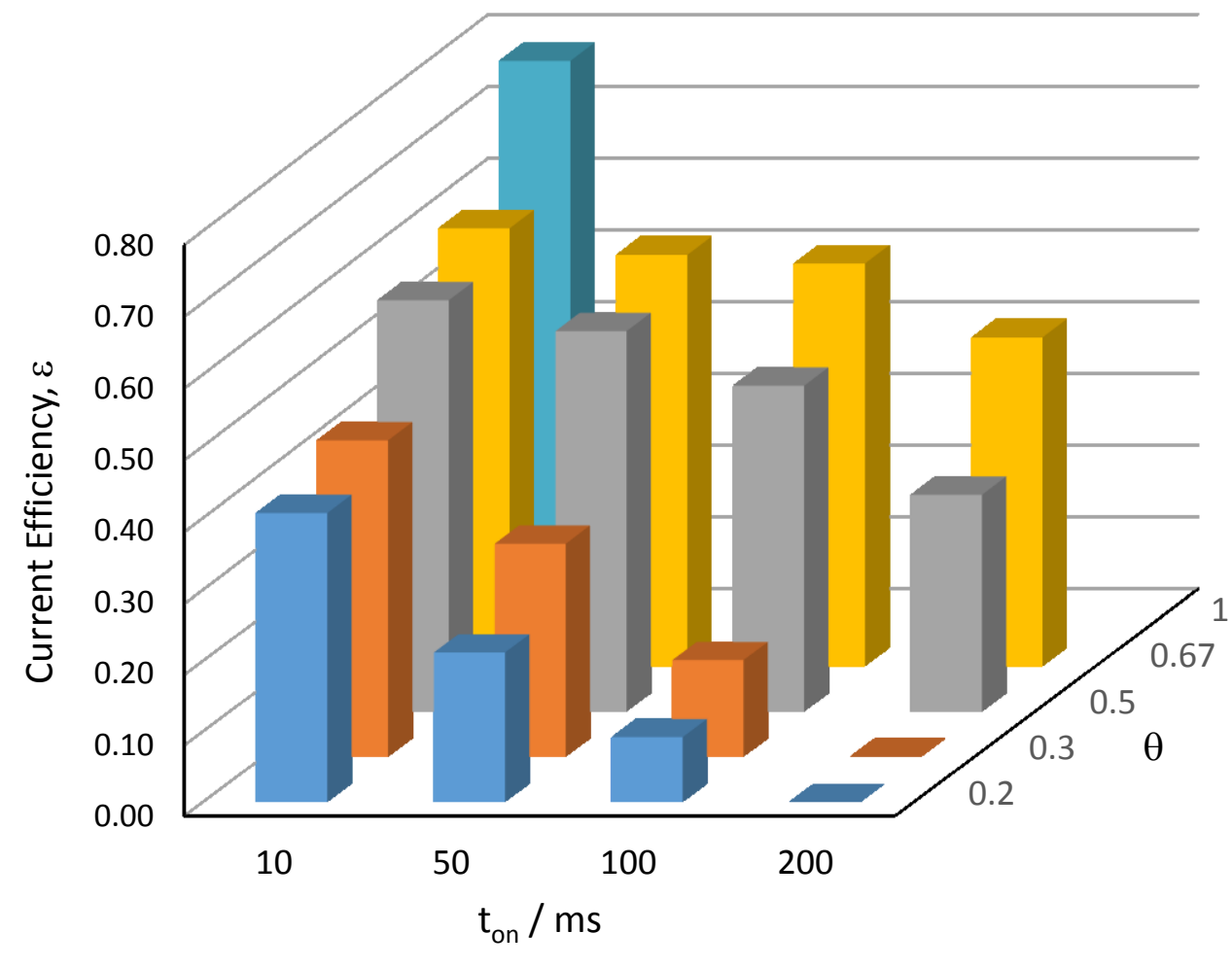

Figure 3: Dependency of the current efficiency, $\varepsilon$, on pulse parameters for the experimental matrix. Note that apparent negative $\varepsilon$ values have been supressed. The column for $\theta=1$ corresponds to DC plating. 


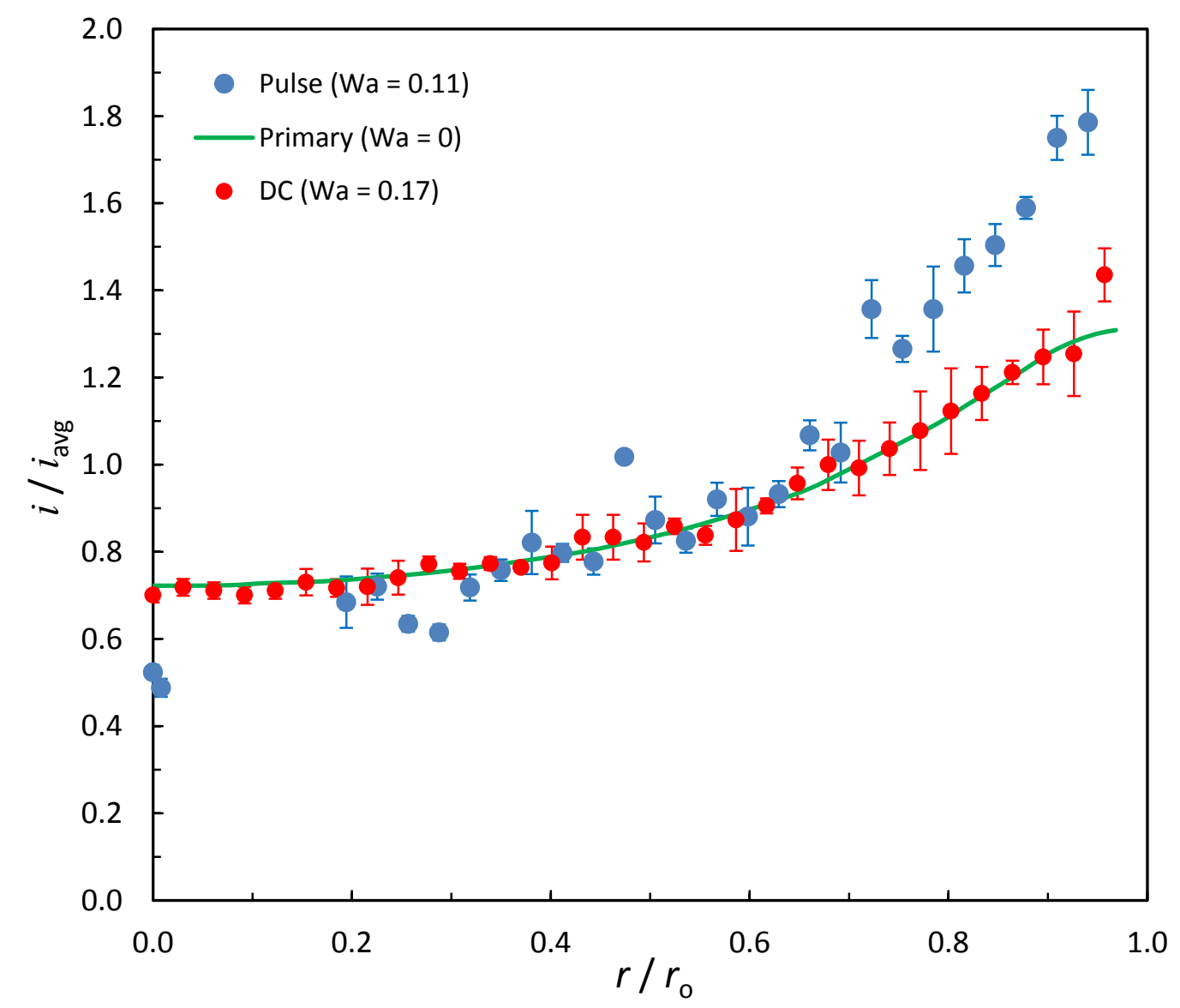

Figure 4: Radial dependence of the current (thickness) distribution at the recessed RDE. The solid line represent the theoretical primary current distribution for a recessed electrode $\left(\mathrm{h} / \mathrm{r}_{0}=\right.$ 0.20). Also shown is the distribution derived from thickness measurements under DC (Wa $=$ $0.17)$ and pulse conditions $\left(t_{\mathrm{on}}=10 \mathrm{~ms}, \theta=0.67\right.$ and $\left.\mathrm{Wa}=0.10\right)$. 

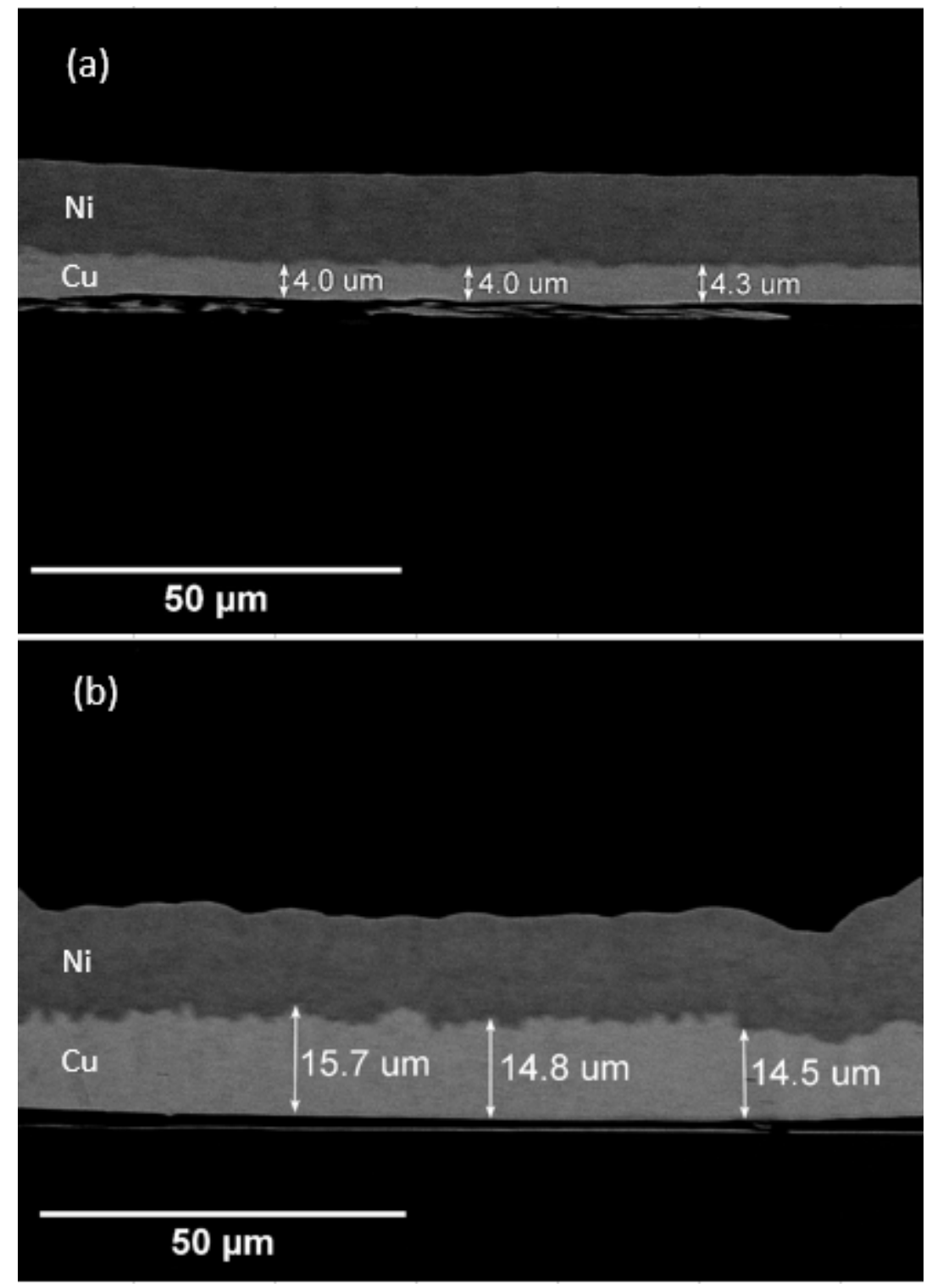

Figure 5: Cross-sectional SEM images of the deposit obtained under pulse conditions $\left(t_{\mathrm{on}}=10\right.$ ms, $\theta=0.67)$ showing the effect of the corrosion reaction on the copper thickness. The electrodeposited coper has been over coated with nickel to assist edge retention. (a) near the disk centre $\left(\mathrm{r} / \mathrm{r}_{0}\right)=0.05$ and $(\mathrm{b})$ near the disk edge $\left(\mathrm{r} / \mathrm{r}_{0}\right)=0.95$. 


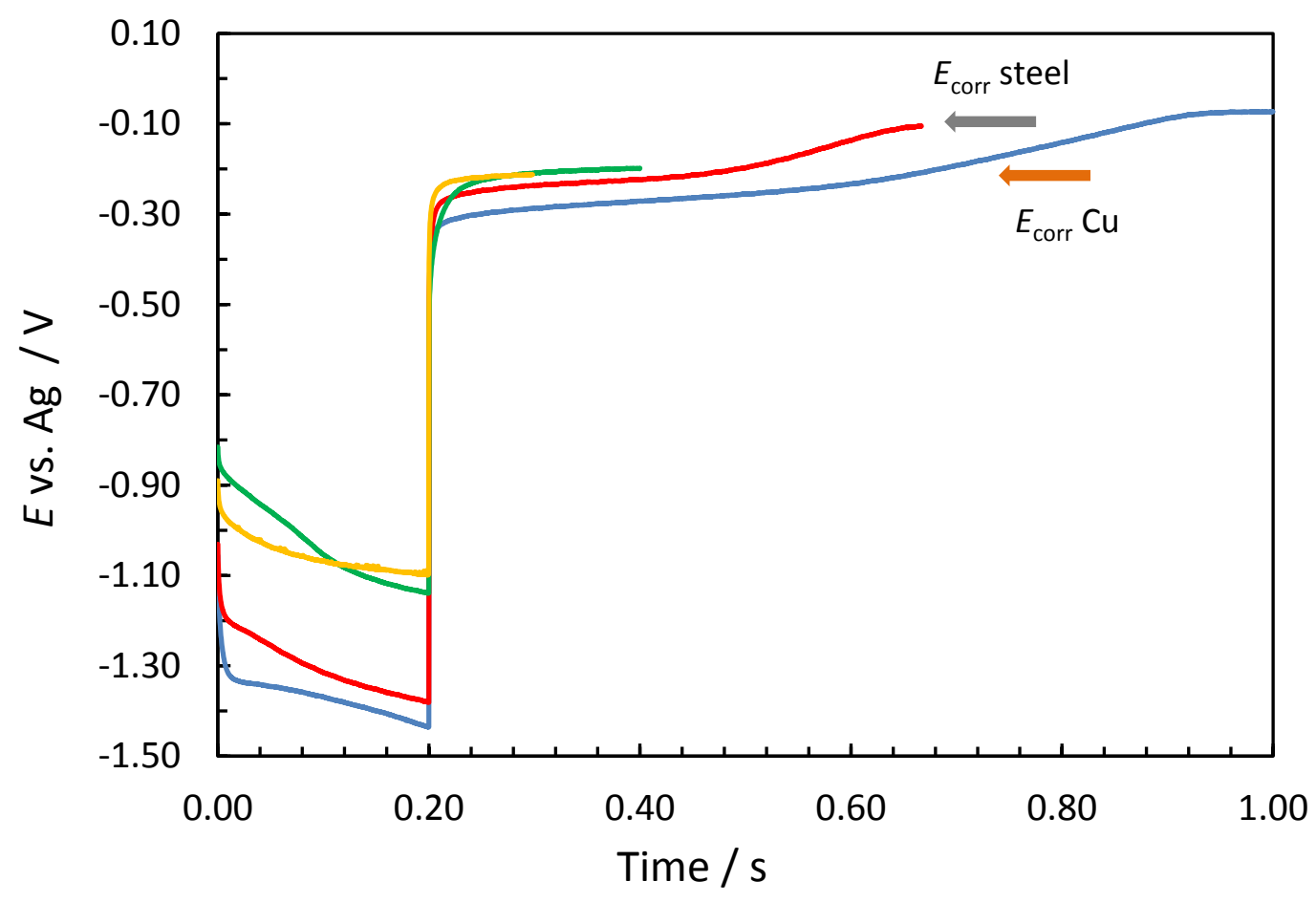

Figure 6: The time dependence of the electrode potential, $E$, during the pulse period for duty cycles of $\theta=0.20,0.30,0.50$ and 0.67 and $t_{\mathrm{on}}=200 \mathrm{~ms}$. Note that the electrode potentials have not been corrected for $I R$ drop. The approximate corrosion potentials of copper and steel are indicated. 


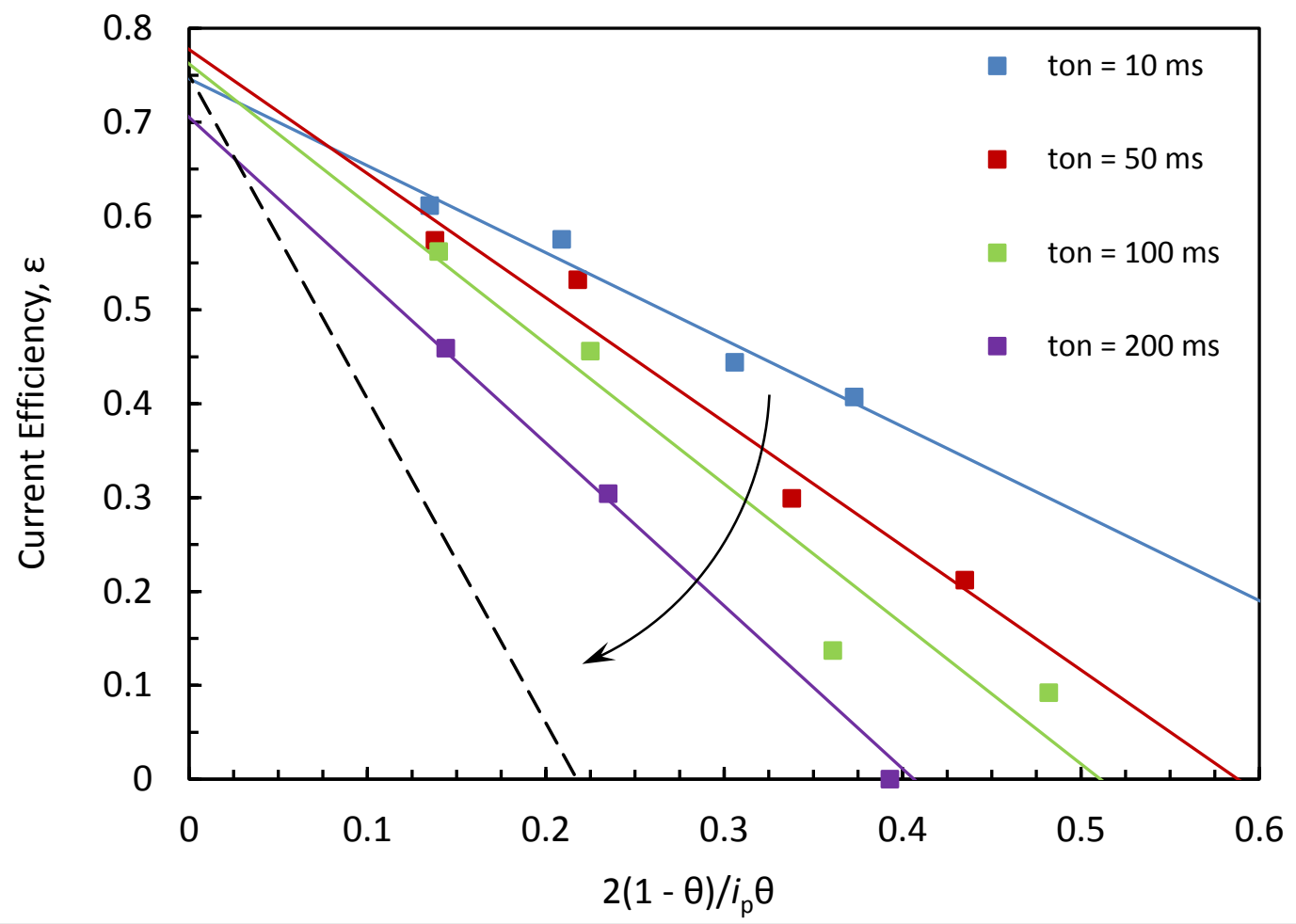

Figure 7: The variation in the apparent current efficiency, $\varepsilon$, as a function of pulse parameters. The dotted line is the expected dependence assuming that $i_{\text {corr }}=i_{\mathrm{LIM}}=3.45 \mathrm{~mA} \mathrm{~cm}^{-2}$. The arrow indicates that $i_{\text {corr }}$ approaches $i_{\text {LIM }}$ as the pulse duration is increased. 


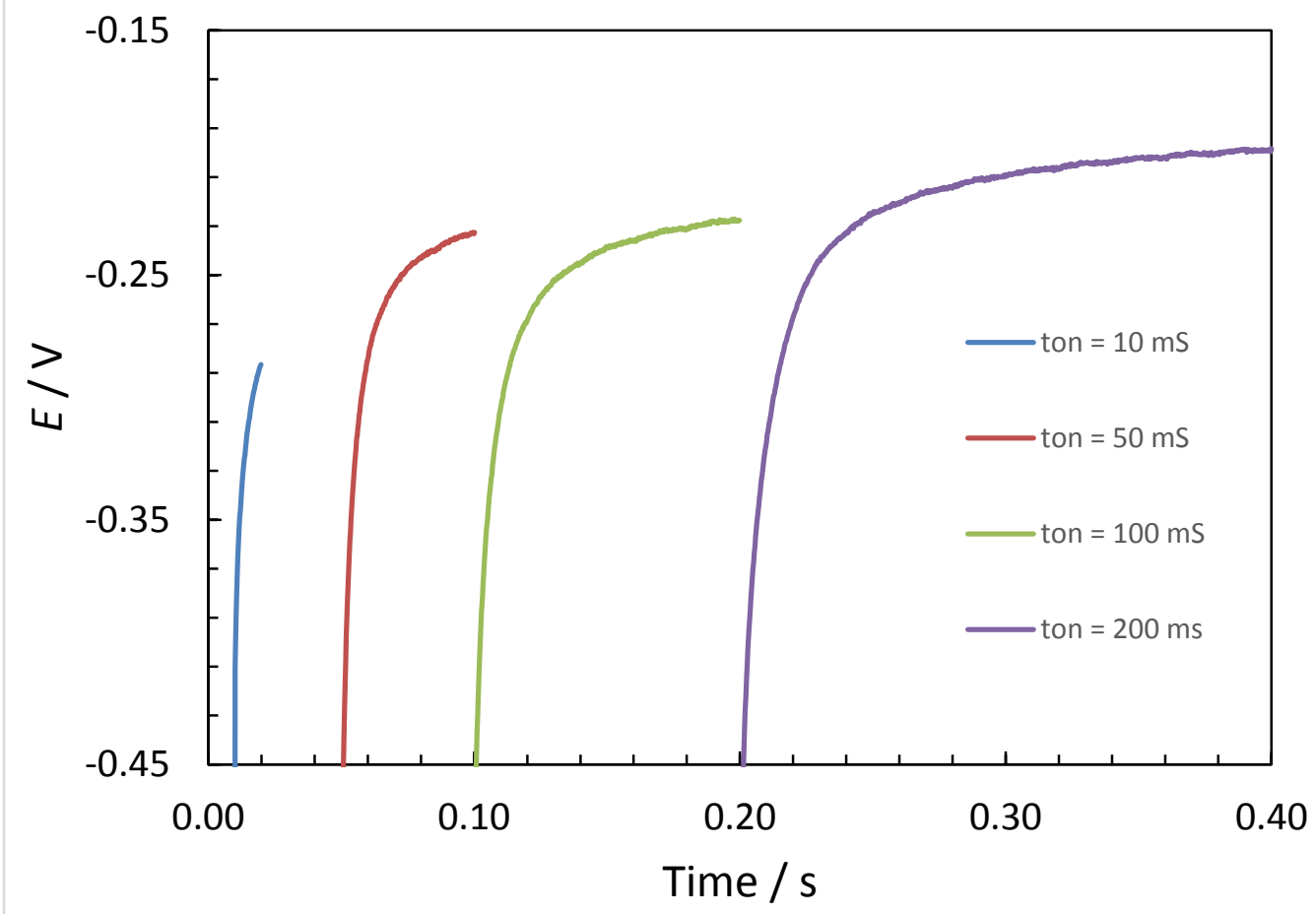

Figure 8: The variation of the potential $E$ in the pulse off-time for $\theta=0.50$ and for a range of on-times. 


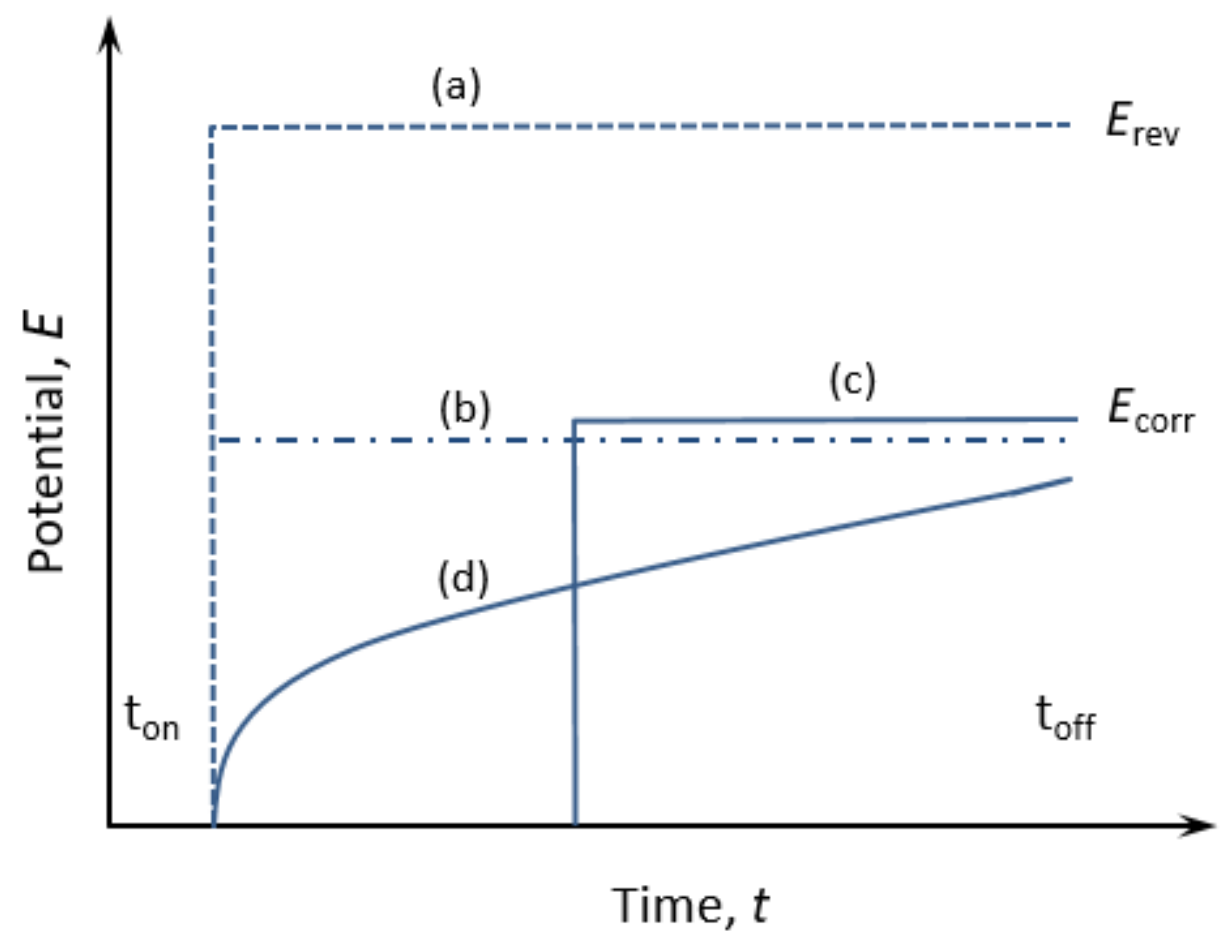

Figure 9: Schematic diagram showing the expected evolution of the potential, $E$, in the offtime for various mechanisms. (a) no corrosion model (b) constant corrosion model (c) corrosion with initial dead-time (d) observed potential transient. 


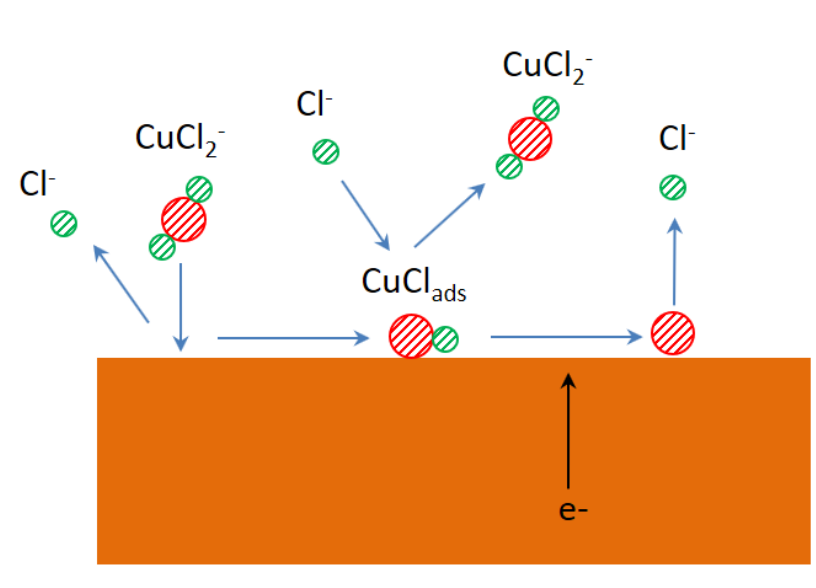

On-time ( $2^{\text {nd }}$ dep step only)

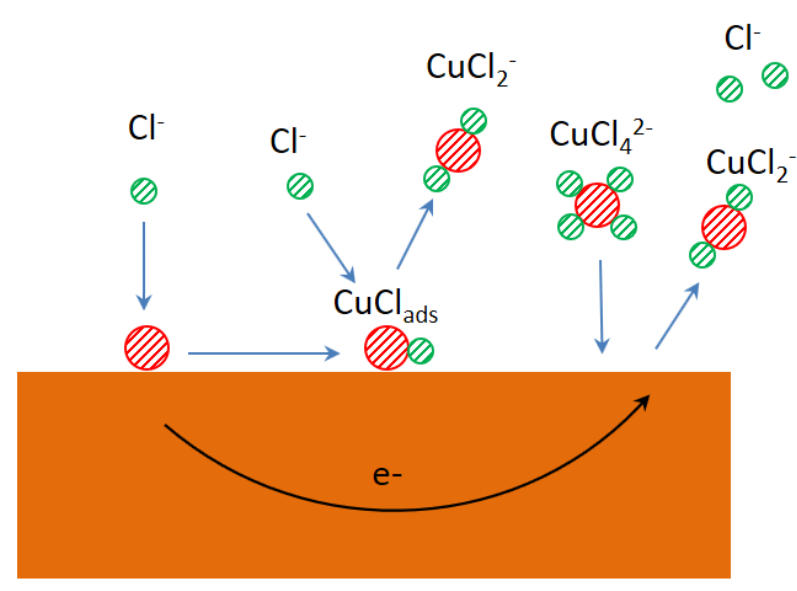

Off-time

Figure 10: Proposed model for the deposition of copper in the on-time and the subsequent corrosion processes in the off-time. For clarity the first reduction step that generates the $\mathrm{CuCl}_{2}{ }^{-}$ species has been omitted from the on-time. 


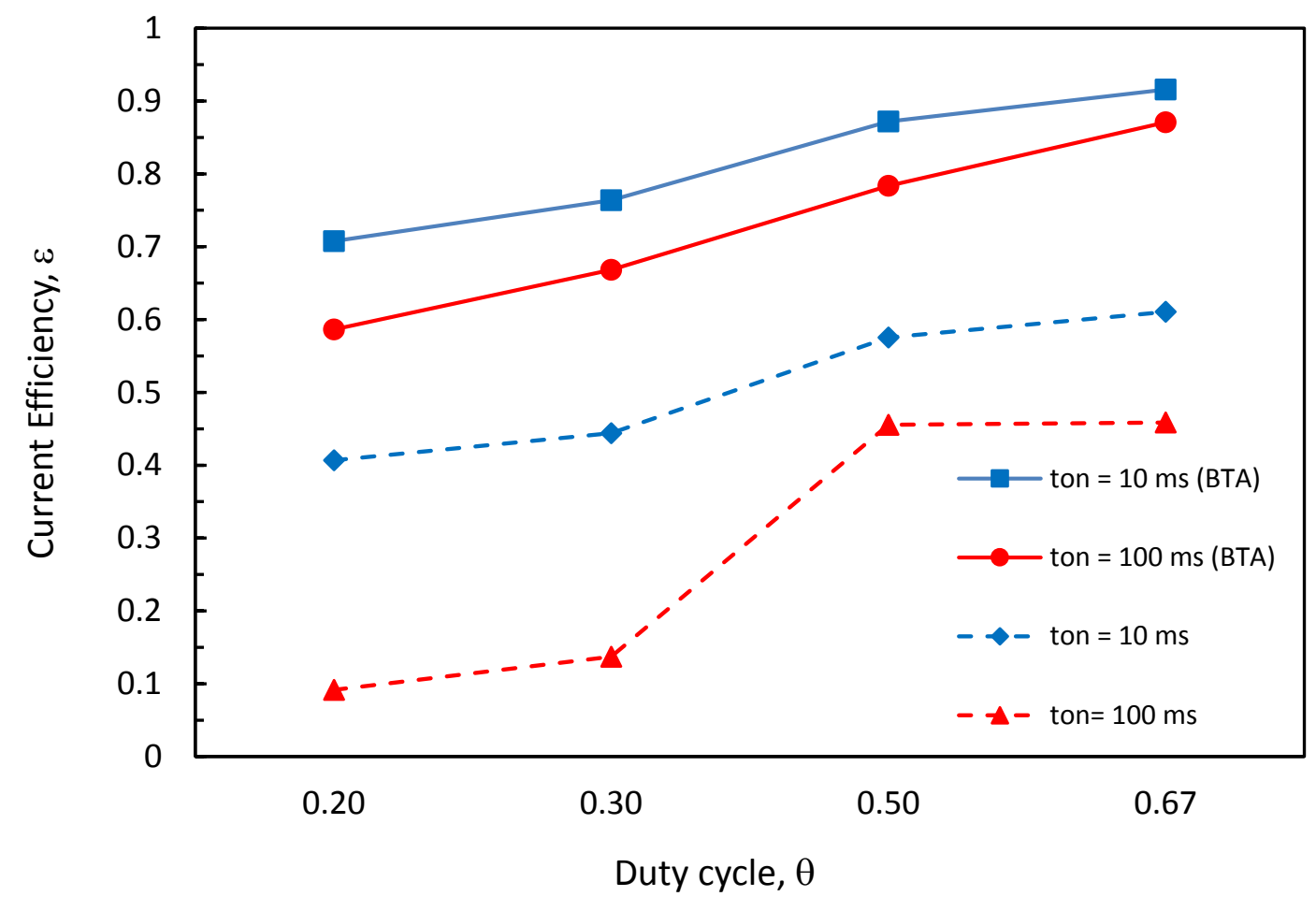

Figure 11: Effect of $10 \mathrm{mM}$ BTA additions on the current efficiency for $t_{\mathrm{on}}=10 \mathrm{~ms}$ and $t_{\mathrm{on}}=$ $100 \mathrm{~ms}$, and for various duty cycles. 


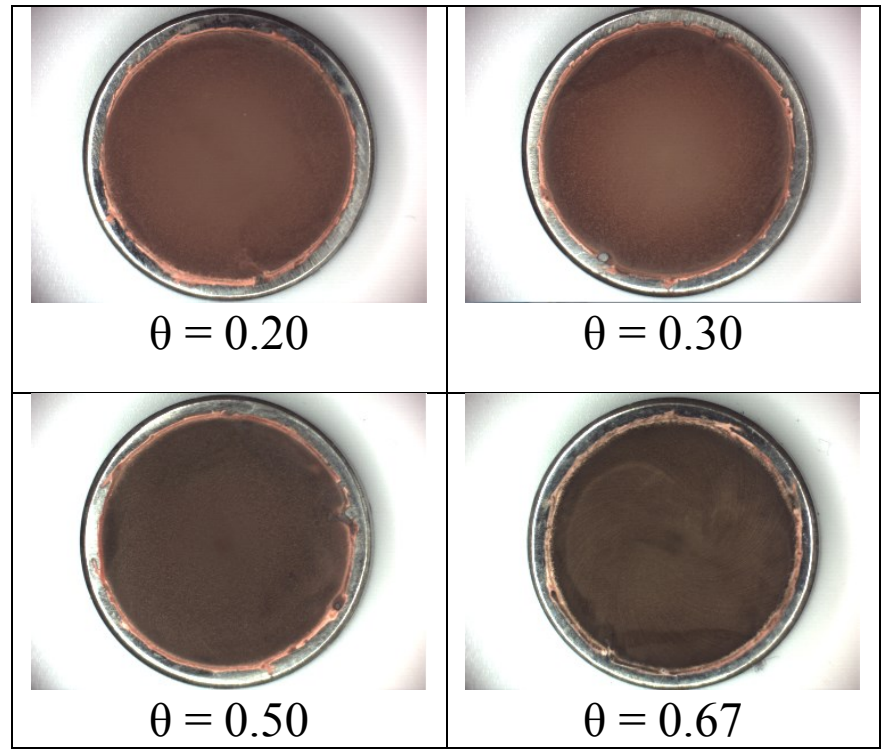

Figure 12: Images of copper deposits in the presence of $10 \mathrm{mM}$ of the BTA additive with $t_{\mathrm{on}}=$ $10 \mathrm{~ms}$ and various duty cycles. 


\begin{tabular}{|c|c|c|c|c|c|}
\hline$\theta$ & $\begin{array}{c}t_{\text {on }} \\
(\mathrm{ms})\end{array}$ & $\mathbf{N}_{\mathbf{m}}$ & $\begin{array}{c}i_{\mathrm{p}} \\
\left(\mathrm{mA} \mathrm{cm}^{-2}\right)\end{array}$ & $\begin{array}{c}t_{\mathrm{c}} \\
(\mathrm{ms})\end{array}$ & $\begin{array}{c}t_{\mathrm{d}} \\
(\mathrm{ms})\end{array}$ \\
\hline 0.2 & 10 & 0.69 & 22.3 & 0.22 & 0.30 \\
\hline 0.3 & 10 & 0.73 & 15.8 & 0.26 & 0.31 \\
\hline 0.5 & 10 & 0.77 & 10.0 & 0.31 & 0.32 \\
\hline 0.67 & 10 & 0.79 & 7.58 & 0.33 & 0.33 \\
\hline 0.2 & 50 & 0.59 & 19.1 & 0.23 & 0.31 \\
\hline 0.3 & 50 & 0.67 & 14.3 & 0.27 & 0.32 \\
\hline 0.5 & 50 & 0.74 & 9.50 & 0.31 & 0.32 \\
\hline 0.67 & 50 & 0.77 & 7.42 & 0.33 & 0.32 \\
\hline 0.2 & 100 & 0.54 & 17.3 & 0.25 & 0.32 \\
\hline 0.3 & 100 & 0.62 & 13.4 & 0.27 & 0.31 \\
\hline 0.5 & 100 & 0.72 & 9.25 & 0.31 & 0.32 \\
\hline 0.67 & 100 & 0.76 & 7.33 & 0.32 & 0.32 \\
\hline 0.2 & 200 & 0.47 & 15.2 & 0.27 & 0.32 \\
\hline 0.3 & 200 & 0.57 & 12.3 & 0.29 & 0.32 \\
\hline 0.5 & 200 & 0.69 & 8.83 & 0.32 & 0.34 \\
\hline 0.67 & 200 & 0.74 & 7.17 & 0.33 & 0.32 \\
\hline
\end{tabular}

Table I: Summary of pulse parameters used in electrodeposition experiments. Note that in all case $\mathrm{N}_{\mathrm{p}}=0.80$. Also included are the calculated charge, $t_{\mathrm{c}}$, and discharge times, $t_{\mathrm{d}}$. 


\begin{tabular}{|c|c|c|}
\hline & $\begin{array}{c}0.20 \mathrm{M} \mathrm{CuSO}_{4} \text { in } \\
1 \mathrm{M} \mathrm{H}_{2} \mathrm{SO}_{4}\end{array}$ & $0.20 \mathrm{M} \mathrm{CuCl}_{2}$ in DES \\
\hline$i_{\text {LIM }}\left(\mathrm{mA} \mathrm{cm}^{-2}\right)$ & 128 & 6.20 \\
\hline$i_{\mathrm{pLIM}}\left(\mathrm{mA} \mathrm{cm}^{-2}\right)$ & 203 & 11.9 \\
\hline$\left.i_{\mathrm{p}}=0.8 \times i_{\mathrm{pLIM}}(\mathrm{mA} \mathrm{cm})^{-2}\right)$ & 160 & 9.5 \\
\hline$i_{\mathrm{av}}\left(\mathrm{mA} \mathrm{cm} \mathrm{cm}^{-2}\right)$ & 80 & 4.8 \\
\hline$t_{\mathrm{c}} \quad(\mathrm{ms})$ & 0.10 & 0.31 \\
\hline$t_{\mathrm{d}}(\mathrm{ms})$ & 0.37 & 0.32 \\
\hline $\mathrm{Wa}$ & 0.23 & 0.08 \\
\hline
\end{tabular}

Table II: Comparison of calculated pulse plating parameters for comparable aqueous and nonaqueous copper systems for $t_{\mathrm{on}}=50 \mathrm{~ms}$ and $\theta=0.50$. For the $\mathrm{CuSO}_{4} / \mathrm{H}_{2} \mathrm{SO}_{4}$, system, the following values ${ }^{1}$ are used: $D=5 \times 10^{-6} \mathrm{~cm}^{2} \mathrm{~s}^{-1}, i_{0}=5 \mathrm{~mA} \mathrm{~cm}{ }^{-2}, \alpha=0.50, C_{\mathrm{dl}}=50 \mu \mathrm{F} \mathrm{cm} \mathrm{cm}^{-2}$ and $\kappa=0.44 \mathrm{~S} \mathrm{~cm}^{-1}$. For $\mathrm{CuCl}_{2} / \mathrm{DES}: D=2 \times 10^{-7} \mathrm{~cm}^{2} \mathrm{~s}^{-1}, i_{0}=5.70 \mathrm{~mA} \mathrm{~cm}{ }^{-2}, \alpha=0.42, C_{\mathrm{dl}}=$ $15 \mu \mathrm{F} \mathrm{cm}^{-2}$ and $\kappa=0.008 \mathrm{~S} \mathrm{~cm}^{-1}$. 


\begin{tabular}{|c|c|c|c|}
\hline $\boldsymbol{t}_{\mathbf{0 n}} / \mathbf{m s}$ & $\boldsymbol{i}_{\text {corr }} / \mathbf{m A ~ \mathbf { ~ c m } ^ { - 2 }}$ & $\mathbf{\%}$ of $\boldsymbol{i}_{\text {LIM }}$ & $\boldsymbol{\varepsilon}$ \\
\hline 10 & 0.71 & 20 & 0.70 \\
\hline 50 & 1.21 & 35 & 0.75 \\
\hline 100 & 1.49 & 43 & 0.76 \\
\hline 200 & 1.71 & 50 & 0.70 \\
\hline
\end{tabular}

Table III: Values of $i_{\text {corr }}$ and current efficiency in the on-time, $\varepsilon$, extracted from the linear plots in Figure 7. 


\section{References}

1. J.-C. Puippe and F. Leaman, Theory and Practice of Pulse Plating, AESF, Orlando, Florida (1986).

2. W.E.G. Hansal and S. Roy, Pulse Plating, Eugen Leuze, Bad Saulgau (2012).

3. A. M. Pesco and H. Y. Cheh, in Modern Aspects of Electrochemistry, Vol. 9, B.E. Conway, J. O’M. Bockris and R. E. White, Editors, Plenum Press, New York (1989).

4. E.J. Taylor, J. Applied Surf. Finish., 3, 178 (2008).

5. N. Ibl, Surf. Technol, 10, 81 (1980).

6. S. Roy, M. Matlosz, and D. Landolt, J. Electrochem. Soc., 141, 1509 (1994).

7. S. Roy and D. Landolt, J. Electrochem. Soc., 142, 3021 (1995).

8. Q. Zhu and C.L. Hussey, J. Electrochem. Soc., 148, C395 (2001).

9. H. Y. Cheh, J. Electrochem. Soc., 118, 551 (1971).

10. T.A. Green, X. Su, and S. Roy, ECS Trans., 77, 1247 (2017).

11. F. Endres, A. Abbott, and D. MacFarlane, Electrodeposition from Ionic Liquids, $2^{\text {nd }}$ edition, Wiley-VCH, Weinheim (2017).

12. A.P. Abbott, G. Frisch, and K.S. Ryder, Annu. Rev. Mater. Res., 43, 335 (2013).

13. A. Ispas and A. Bund, Trans. IMF, 90, 298 (2012).

14. A. Ispas and A. Bund, Interface, Spring 2014.

15. M. Manolova and R. Bock, Trans. IMF, 97, 161 (2019).

16. W. Dean, J. Klein, and B. Gurkan, J. Electrochem. Soc., 168, 026503 (2021).

17. J.-C. Puippe, Trans. IMF, 96, 244 (2017).

18. S. Roy and D. Landolt, J. Appl. Electrochem., 27, 299 (1997).

19. T.A. Green and S. Roy, Trans. IMF, 95, 46 (2017).

20. O. Chene and D. Landolt, J. Appl. Electrochem., 29, 188 (1989).

21. J. Cl. Puippe and N. Ibl, J. Appl. Electrochem., 10, 775 (1980). 
22. P.E. Valverde, T.A. Green, and S. Roy, J. Appl. Electrochem., 50, 669 (2020).

23. A. Mandroyan, M. Mourad-Mahmoud, M-L. Doche and J-Y. Hihn, Ultrason. Sonochem., 21, 2010 (2014).

24. A.P. Abbott, K. El Ttaib, G. Frisch, K.J. McKenzie, and K.S. Ryder, Phys. Chem. Chem. Phys., 11, 4269 (2009).

25. D. Lloyd, T. Vainikka, L. Murtomaki, K. Kontturi, and E. Ahlberg, Electrochim. Acta., 56, $4942(2011)$.

26. D. Shen, K. Steinberg, and R. Akolkar, J. Electrochem. Soc., 165, E808 (2018).

27. J. Newman, J. Electrochem. Soc., 113, 1235 (1966).

28. T.E. Dinan, M. Matlosz, and D. Landolt, J. Electrochem. Soc., 138, 2947 (1991).

29. T.A. Green, P. Valverde, and S. Roy, J. Electrochem. Soc., 165, D313 (2018).

30. M. Georgiadou and R. Alkire, J. Electrochem. Soc., 140, 1340 (1993).

31. C.W. Yeow and D.B. Hibbert, J. Electrochem. Soc., 130, 786 (1983).

32. H.K. Lin, X.J. Wu and P.D. Rao, JOM, 43, 60 (1991).

33. H.P. Lee and K. Nobe, J. Electrochem. Soc., 133, 2035 (1986).

34. E. D’Elia, O.E. Barcia, O.R. Mattos, N. Pebere, and B. Tribollet, J. Electrochem. Soc., 143, $961(1996)$

35. F.K. Crundwell, Electrochim. Acta., 37, 2707 (1992).

36. A.P. Abbott, G. Frisch, J. Hartley, W.O. Karim, and K.S. Ryder, Progress in Natural Science: Materials International, 25, 595 (2015).

37. J.J. Kelly, P.E. Bradley, and D. Landolt, J. Electrochem. Soc., 147, 2975 (2000).

38. M. Finsgar and I Milosev, Corrosion Science, 52, 2737 (2010).

39. N. Tantavichet and M. Pritzker, J. Appl. Electrochem., 36, 49 (2006).

40. J.L. Guinon, J. Garcia-Anton and V. Perez-Herranz, J. Appl. Electrochem., 30, 379 (2000). 